\title{
Screen printing with tamarind seed gum on cotton fabric
}

Sudha Babel, Rupali Gupta and Latika Sachihar

Received: 22.10.2017; Revised: 03.04.2018; Accepted: 20.04.2018

See end of the paper for authors' affiliations

\section{Sudha Babel}

Department of Textile and Apparel Designing, College of

Home Science, Maharana Pratap

University of Agriculture and

Technology, Udaipur (Rajasthan) India
DABSTRACT : The most commonly used thickeners for printing cotton fabric is synthetic, but in view of eco friendly nature, partly substituting tamarind kernel powder represents an acceptable alternative. Therefore, an attempt was made to screen print cotton fabric with tamarind kernel powder with different concentration, evaluate the visual appearance of printed fabric for various parameters. Results revealed that 10 per cent concentration of thickening agent showed best results in terms of colour fastness to washing, perspiration and light and also possessed good physical characteristics. So this concentration of thickening agent was finally selected for the screen printing.

KEY WORDS: Tamarind kernel powder, Screen printing, Colour fastness properties

- HOW TO CITE THIS PAPER : Babel, Sudha, Gupta, Rupali and Sachihar, Latika (2018). Screen printing with tamarind seed gum on cotton fabric. Asian J. Home Sci., 13 (1) : 180-186, DOI: 10.15740/ HAS/AJHS/13.1/180-186. Copyright@ 2018: Hind Agri-Horticultural Society. 